AÜiFD 47 (2006), sayı 2, s. 89-98.

\title{
Bir Türk Düş̧ünürüi Olarak Ziya Gökalp: Hayatı, Kişiliği ve Düşünnce Yapısı Üzerine Bir İnceleme
}

\author{
ŞAHIN GÜRSOY - İHSAN ÇAPCIOĞLU \\ DR., A. Ü. SOSYAL BİL. ENS. - AR. GÖR., A. Ü. İLAHIYAT FAKÜLTESI \\ e-mail: sahingursoy@yahoo.com - ihsancapcioglu@yahoo.com
}

\begin{abstract}
Ziya Gökalp as a Turkish Thinker: A Study on His Life, Personality, and Philosophy. Born March 23, 1876 in Diyarbakır, Ziya Gökalp is one of the most prominent figures in the history of Turkish philosophy, culture and politics. Living in a period of transition from an Empire to a Nation-State, sociological, cultural and political theories and assessments made by Gökalp about the Turkish society and Turkish culture under the influence of problems and troubles encountered still maintain their currency and validity. This is because many of Gökalp's political, religious and cultural ideas and suggestions have been realized with the newly established Republic. There is no doubt that Western perceptions were also influential on Gökalp's such social approaches.
\end{abstract}

key words: Turkism, Nationalism, Turkish Society, Republic, Nation-State, Ummah.

\section{Hayatı ve Kişiliği}

Ziya Gökalp, 23 Mart 1876 yılında Diyarbakır'da doğmuştur. ${ }^{1}$ Kendisine, babasının isteği üzerine Mehmet Ziya ismi verilmiştir. Babası, Vilayet Evrak Memuru Mehmet Tevfik Efendi (1851-1890), annesi Zeliha Hanım'dır (18561923). İlköğrenimini 1883 yazında kayıt yaptırdığı Mercimekörtmesi Mahalle Mektebi'nde tamamlamıştır. Hürriyetle ilgili ilk fikirlerini ise 1886 y1lında girdiği Mektebi Rüştiye-i Askeriyye'de (Askeri Lise) hocası Kolağası

1 Hilmi Ziya Ülken, Türkiye'de Çağdaş Düşünce Tarihi, İstanbul, 2001, s. 304; Hikmet Tanyu, Ziya Gökalp'in Kronolojisi, Ankara, 1981, s. 1-3; Cavit Binbaşıoğlu, Türkiye'de Eğitim Bilimleri Tarihi, İstanbul, 1995, s. 121. 
İsmail Hakkı Bey'den edinmiştir. ${ }^{2} 1890$ yılında amcası Müderris Hacı Hasip Bey'den dersler almaya başlayan Gökalp, 1891 yılında ikinci sınıftan kayıt yaptırarak İdadi-i Mülkiye'ye başlamıştır. 1893 yılında öğretmeni Doktor Yogi'den felsefe dersleri, Maarif Müdürlüğü ve İdadi'de (orta öğretim) tarih öğretmenliği yapan Mehmet Ali Ayni'den ise tarih dersleri almıştır. Ziya Gökalp, Mehmet Ali Ayni'den gördüğü derslerde tarihin nasıl muhakeme edileceğini öğrenmiştir. Fakat İdadi'nin 7 yıla çıkartılması üzerine Gökalp, buradan ayrılmıştır. Toplumun yaşadığı sıkıntıların üzerinde bıraktığı izlerin yanı sıra, ${ }^{3}$ ekonomik olanaksızlıklar yüzünden İstanbul'da öğrenimine devam edememesi ve ailesinin evlilik baskıları gibi nedenler Ziya Gökalp’i bunalıma sürükleyince, 1894 yllında intihar girişiminde bulunmuştur. ${ }^{4}$ Hilmi Ziya Ülken, Gökalp'in intihar sebebi olarak, Hocası Dr. Yorgi Efendi'den aldığı felsefe eğitimi ile ailesinden aldığ dini muhafazakar eğitim arasında yaşadığı çatışmayı göstermektedir. ${ }^{5}$

Intihar olayından sonra kendini tekrar okumaya ve bilime veren Gökalp, eğitimine devam etme isteğiyle 1895 yılında kardeşi ile birlikte yeniden İstanbul'a gelmiştir. Fakat parası olmadığı için ancak ücretsiz olan Veteriner Mektebine kayıt yaptırabilmiştir. Gökalp, İstanbul'da bulunduğu bu dönemde Batı kültürünü de tanımaya yönelmiştir. ${ }^{6}$ Okulda yasak yayınları okuması ve farklı çıkışları ile dikkati çeken Gökalp, 1899 yılında geçirdiği soruşturmanın ardından 'yasak kitapları okuma ve zararlı derneklere üye olma' gerekçesiyle cezaevine gönderilmiştir. 12 aylık cezaevi yaşamından sonra, okuldan da uzaklaştırılarak Diyarbakır'a sürülmüştür. 1900 yılında amcasının kızı ile evlenerek Diyarbakır'a yerleşen Gökalp, küçük memuriyetlerde çalışmaya başlamıştır. Bu dönemde Gökalp, bir taraftan eşinin mal varlığı ile rahat bir hayat yaşamaya başlamış; diğer taraftan ise, el altından hürriyet çalışmalarını sürdürmeye devam etmiştir. 1903 yılından sonra Diyarbakır Ticaret Odası'nda çeşitli görevlerde bulunmuş; bu sırada, Vilayet Gazetesi Başyazarlığı görevini de yürütmüştür. 1905 yılında, halka yaptığı kötülükler dolayısıyla aşiret reisi İbrahim Paşa'ya karşı çıarak halkı ona karşı ayaklandırmıştır. ${ }^{7}$

2 Tanyu, a.g.e., s. 3-8; Mustafa Ergün, II. Meșrutiyet Devrinde Eğitim Hareketleri (1908-1914), Ankara, 1996, s. 136; Ali Nüzhet, Ziya Gökalp’in Hayatı ve Malta Mektupları, İstanbul, 1931, s. 14-17. Ali Nüzhet, Ziya Gökalp'in damadı olup ölümünden sonra O'nun birçok yazısını ve mektuplarını derleyerek yayınlamıştır.

3 Cavit Orhan Tütengil, Ziya Gökalp Üzerine Notlar, İstanbul, 1956, s. 6.

4 Ali Nüzhet, a.g.e., s. 21.

5 Ülken, a.g.e., s. 304.

6 Hasan Tuncay, Ziya Gökalp, İstanbul, 1978, s. 34.

7 Tuncay, a.g.e., s. 45-46. 
Ziya Gökalp, 1908'de İttihat ve Terakki'nin Diyarbakır, Van ve Bitlis heyetlerinin müfettişliğine atanmıştır. ${ }^{8} 1909$ yılında Darülfünun'da hocalık yapmak üzere İstanbul'a gelen Gökalp; orada birkaç ay kalmış, yeterli ücret alamadığı için tekrar Diyarbakır'a dönerek, "Peyman" gazetesini çıkarmaya başlamıştır. ${ }^{9} 1909$ yılının son aylarında ise İttihat ve Terakki tarafından Selanik'e gönderilmiştir. ${ }^{10}$

Ziya Gökalp, 1912'de ailesi ile birlikte bir kez daha İstanbul'a yerleşmiştir. ${ }^{11} \mathrm{Bu}$ dönemde, Darülfünun ve Eğitim Fakültesinde Gökalp'in eğitimle ilgili görüşleri kabul edilmiş; ders programları, okutulacak dersler ve kitaplar onun önerileri doğrultusunda kararlaştırılmıştır. ${ }^{12}$ Bu dönemden itibaren düşüncelerini ve çalışmalarını Türkçülük etrafında şekillendiren Gökalp, aynı zamanda hayatının en yaratıcı dönemini de yaşamıştır. 1913 ve 1914 yıllarında kendisine teklif edilen Maarif Nazırlığı (Milli Eğitim Bakanlığı) görevini kabul etmemiş, Edebiyat Fakültesinde İctimaiyyat Müderrisliği (Sosyoloji Hocalığı) görevine devam etmiştir. Bu göreviyle birlikte Gökalp, İstanbul Üniversitesi'nde ilk sosyoloji profesörü olmuştur.

Gökalp'in Kızılelma adlı eseri 1914'de yayınlanmıştır. 1917'de "Yeni Mecmua” yayın hayatına başlamıştır. 1918'de ise Türkleşmek, İslamlaşmak, Muasırlaşmak adlı eseri ile Yeni Hayat isimli şiir kitabını yayınlamıştır.

8 Binbaşı̆̆lu, a.g.e., s. 121.

9 Ziya Gökalp, 48 yıllık kısa yaşam serüveninde çok sayıda kitap ve makale yayınlamış, bazı gazete ve dergilerin yayımlanmasına öncülük etmiş ve yazılarıyla katkıda bulunmuştur. Onun başlıca eserleri şunlardır: Kızıl Elma, İstanbul, 1914-1915; Türkleşmek İslamlaşmak Muasırlaşmak, İstanbul, 1918; Yeni Hayat, İstanbul, 1918; Altın Işık, İstanbul, 1923; Türkçülüğün Esasları, Ankara, 1923; Türk Töresi, İstanbul, 1923; Doğru Yol, Ankara, 1923; Kürt Aşiretleri Hakkında Sosyolojik Tetkikler (Gökalp, bu incelemesini, İttihat ve Terakki Partisi'nin isteğiyle 1909 yılında yapmıştır. Kitabın sonunda "Diyarbakır, Haziran 1909" notu vardır (s. 166), ancak çalışma ölümünden sonra yayınlanmıştır. Yine ölümünden sonra değişik gazete ve dergilerde yayımlanmış yazılarıyla mektupları çeşitli kitaplarda derlenmiştir. Bunlar; Türk Medeniyeti Tarihi, (1926), Çınaraltı (1939), Furka Nedir? (1947), Ziya Gökalp Diyor ki (1950). Ziya Gökalp’nn Neşredilmemiş Yedi Eseri ve Aile Mektupları (1956), Ziya Gökalp'ın Yazarlık Hayatı (1956), Ziya Gökalp Külliyatı (1. Kitap Şïrler ve Halk Masalları, 1952; 2. Kitap Limni ve Malta Mektupları, 1965), Turkish Nationalism and Western Civilization: Selected Essays, (Çeviri ve giriş yazısı: Niyazi Berkes), New York: Columbia Univ. Press, (1959), Ziya Gökalp’ın İlk Yazı Hayatı, 1894-1909: Doğumu'nun 80. Yıldönümü Münasebetiyle (1956), Terbiyenin Sosyal ve Kültürel Temelleri (1973) sseklinde sıralanabilir. Ziya Gökalp'in yazılarıyla katkıda bulunduğu ya da yayımlanmasına öncülük ettiği dergiler; Yeni Mecmua, Genç Kalemler, Küçük Mecmua, Türk Yurdu, İctimaiyat Mecmuası, İslam Mecmuası, Edebiyat Fakültesi Mecmuası, İlim, Felsefe, Fen Tetebbuatı Mecmuası, Halka Doğru Mecmuası, Muallim Mecmuası, Şair Mecmuası ve Milli Tetebbular Mecmuası'dır. Gökalp'in yazılarını yayınladığı başlıca gazeteler ise şunlardır: Dicle, Diyarbakır, Şurayı Ümmet, Tanin, Peyman, Cumhuriyet, Akşam, Yeni Türkiye, Rumeli, Yeni Gün, Hakimiyet-i Milliye ve Donanma. Bunların dışında Gökalp, değişik takma ad ve lakaplar kullandığı yazılar da yayınlamıştır.

10 Ali Nüzhet, a.g.e., s. 47.

11 Tanyu, a.g.e., s. 75.

12 Binbaşıŏlu, a.g.e., s. 121. 
1919 yılının Ocak ayında, 'asayişi bozma ve Ermenilere zor kullanma' iddiasıyla Divan-1 Harp'te (askeri mahkeme) idam cezası ile yargılanan Gökalp, idam cezası almamış, ancak Malta'ya sürülmüştür. Malta'da çok sıkıntılı bir yaşam süren Gökalp, sürgün döneminde çalışmalarına bir süre ara vermek zorunda kalmıştır. 30 Nisan 1921'de Kars Savaşında esir alınan İngilizlerin karşılığında Malta'da esir Türklerin serbest bırakılması ile birlikte Yurda dönerek Diyarbakır'a yerleşmiştir.

1922'de Muallim Mekteb'inde (Eğitim Fakültesi) felsefe dersleri vermeye başlayan Gökalp, bir taraftan da dergi çıkarma çalışmalarına devam etmiştir. Bu dönemde, Ahmet Ağaoğlu'nun desteği ile "Küçük Mecmua" dergisini çıkarmıştır. Derginin ilk sayısında, tarihi, kültürel, dinsel ve coğrafi birliktelikleri nedeniyle Türkler ve Kürtlerin birbirlerini sevmelerini bir zorunluluk olarak kabul ettiği "Türkler ve Kürtler" adlı makalesini kaleme almıştır. ${ }^{13}$

1923 yılında Telif ve Tercüme Encümeni Reisliği’ne (Kültürel Yayınlar Dairesi Müdürlüğü) getirilen Ziya Gökalp; aynı yıl, Türkçülü̆̆ün Esasları isimli ünlü eserini yayınlamıştır. 11 Ağustos 1923 tarihinde Diyarbakır'dan Milletvekili seçilen Gökalp; bilimsel, kültürel ve eğitim çalışmalarına ara vermiş gibi görünse de, yine bu dönemde de kültürel ve düşünsel çalışmalarına devam etmiştir. Bu bağlamda, "Yeni Türkiye" dergisini çıkarmış, anayasanın hazırlanmasına yardım etmiş, Türk Medeniyeti Tarihi'ni tamamlamaya çalışmış ${ }^{14}$ ve Türk dili çalışmalarına katkılarda bulunmuştur. Bu süreçte Gökalp, milli edebiyatın geliştirilmesi yönünde de çaba harcamıştır.

Yine, Yeni Türkiye'nin Hedefleri isimli eserini de bu dönemde yayınlamıştır. Hastalandığı dönemde de Türk Medeniyeti Tarihi ve Çınaraltı isimli çalışmalarını sürdürmüş̧; hatta tedavi için İstanbul'a, Maarif Vekâleti'nden (Milli Eğitim Bakanlığı) Türk Medeniyeti Tarihi'nin basımı için aldığı avansla gidebilmiştir. 1924 yılı başlarında rahatsızlanan Gökalp, 25 Ekim 1924 tarihinde vefat etmiştir. ${ }^{15}$

Ziya Gökalp, günlük yaşamda içe dönük, sakin ve kendi halinde birisi olmuştur. Buna karşın, idealist ve mücadeleci bir yapıya sahip olan Gökalp, en kötü durumlarda bile ümidini kaybetmeyecek kadar kararlı bir kişiliğe sahiptir. Yaşamı boyunca, düşünce ve hayalleri yolunda mücadele vermiş; hiçbir dönem, düşünce ve eylemlerinden ödün verme gereği duymamıştır. Birçok kovuşturma, hapis ve sürgün cezasıyla karşılaşmasının arkasında da yine bu kararlı tutumunun etkileri vardır. Gençlik döneminde, Sultana karşı

13 Ali Nüzhet, a.g.e., s. 166-167

14 Tuncay, Ziya Gökalp, s. 61

15 Tanyu, a.g.e., s. 156-161. 
söz söylemek ve eylemde bulunmaktan çekinmeyen Gökalp; önemli düşünsel yakınlıklara rağmen, Meclise girdiği dönemde Atatürk'e de çok yakın olma gereği duymamıştır. Gençlik yıllarına denk düşen bir dönemde yaşadığı bir bunalım durumu dışında, Gökalp'in yaşamı hep sosyal ve siyasal mücadele ile geçmiştir. Aynı şekilde, en bunalımlı günlerinde bile Ülkenin kurtulacağına olan güveni tam olmuştur. Ziya Gökalp'in en güçlü yönlerinden biri de, hiç kuşku yok ki; onun hayal gücüdür. Gökalp'i, düşünce insanı, maneviyatçı, toplumsal ve ahlaki konularda eylem adamı ve şair yapan çoğunlukla bu yüksek hayal ve düşünebilme gücü olmuştur. ${ }^{16}$

Güçlü bir analitik düşünce yeteneğine sahip olan ve vatan sevgisiyle dolu duygu ve düşünce yüklü şiirler yazan Gökalp, aynı zamanda sorumlu bir aile babasıdır. Yaşamının sonlarına doğru, hayatının en zor dönemini yaşadığı hastalık günlerinde, tedavi masraflarının karşılanmasıyla ilgili olarak Atatürk'ten aldığı teklife karşılık, kendisinden sonra eşine ve kızlarına yardım edilmesini istemesi bunun açık örneklerinden biridir.

\section{Düşünce Yapısı ve Türkçülük Anlayışı}

Birçok çağdaşı Türk aydını gibi Ziya Gökalp’in düşünsel yapısı üzerinde de, Osmanlı Devleti'nin parçalanma sürecine girdiği dönemde baş gösteren siyasal, askeri, dinsel ve ekonomik sorunların derin izlerini görmek mümkündür. Bu etkilerin de tesiriyle, Gökalp’in düşünce yapısı içerisinde ulusçuluk anlayışı önemli bir yere sahip olmuştur. Fakat Gökalp'in ulusçuluğu, etnik temelli değil; kültürel bir ulusçuluktur.

Çok farklı alanlarda eserler veren Ziya Gökalp'in düşünce ikliminin oluşum sürecinde aile çevresi, İsmail Hakkı Bey, Yorgi Efendi, İbrahim Temo, Dr. Abdullah Cevdet, İshak Sukuti ve Naim Beylerin yanı sıra; Genç Türklerin de etkisi olduğu bilinmektedir. Gökalp, düşünsel yaklaşımı dolayısıyla İttihat ve Terakki Cemiyetinde çeşitli kademelerde görevlerde de bulunmuştur. Aynı şekilde, Durkheim'ın sosyolojik yaklaşımları da Gökalp'in düşünceleri üzerinde önemli izler bırakmıştır. ${ }^{17}$

Babası Tevfik Efendi, edebiyata meraklı ve oğlunun en iyi şekilde yetişmesi için çaba sarf eden biridir. Gökalp'in edebiyat merakının da babasından geçtiği söylenebilir. ${ }^{18}$ Avrupa'da Yetişen gençleri kültürlerine yabancı kaldıkları, medresedeki öğrencileri de dünyadaki gelişmelerden haberdar 
olmadıkları gerekçesiyle eleştiren Tevfik Efendi, oğlundan Doğu değerlerini özümseyip, Müslüman kalarak Batılı bir eğitim almasını ve her iki kültürü de öğrenip bunları kıyas ve telif etmesini istemiştir. Tevfik Efendi'nin bu tutumunun Ziya Gökalp'in hayatındaki etkileri büyük olmuştur. ${ }^{19} 28$ Aralık 1888'de Namık Kemal'in vefatı üzerine; Tevfik Efendi'nin oğluna, onun gibi hürriyetçi ve vatansever olmayı ögütlemesi de Gökalp'in hayatındaki önemli dönüm noktalarından birisidir. ${ }^{20}$ Bununla birlikte, annesi ve babaannesinin de, aldıkları eğitim ve geldikleri muhitin de etkisiyle Gökalp'in üzerinde en az babası kadar etkili ve yönlendirici olduklarını belirtmek gerekir. ${ }^{21}$

Diyarbakır'da özel felsefe dersleri aldığı Dr. Yorgi Efendi, İstanbul'a gelince, Gökalp ve arkadaşları ile bir toplantı yapmıştır. Onlarla yaptığı bir sohbette Türk gençlerinin Meşrutiyeti kurmak için çalıştıklarını, bunun övgüye değer bir gayret olduğunu belirtmiştir. Yapılacak devrimin faydalı ve etkili olabilmesi için mutlaka ülkenin sosyolojik ve psikolojik yapısına uygun olması gerektiğini ifade eden hocasının bu vasiyeti, Gökalp'in yapmayı düşündükleri üzerinde yönlendirici bir etkiye sahip olmuştur. ${ }^{22}$

1899-1900 yıllarında tutuklu bulunduğu sırada tanıştığı Naim Bey, Gökalp üzerinde önemli etkiler bırakan simalardan bir diğeridir. Naim Bey, Meşrutiyetin mutlaka ilan edileceğini, ama ilk meşrutiyetin uzun süreli olmayacağını; Meclisin, entrikalar ve rant kavgaları sonucu kapatılacağını söylemiştir. Ona göre, meclisin kapanmasında en önemli neden, derin bir uykuda olan halkın meşrutiyetin kıymetini bilmemesidir. Halka, meşrutiyetin gereği anlatılmalıdır. Bunun da tek yolu özgür basındır. Gökalp, basının özgürleştirilmesini rastladığı her gence öğütlediğini belirtmiştir. ${ }^{23}$ Kendisine, Naim Bey'in vasiyetini rehber kabul eden Gökalp; onu, kendisi için bir pir (akıl hocası) olarak nitelendirmiştir. Gökalp, bu vasiyeti kendinden sonra gelecek gençlere, Türkçü bilginin vasiyeti olarak sunmuştur. ${ }^{24}$

İdadi (orta öğretim) yıllarından itibaren felsefe ve sosyal bilimlere ilgi duymaya başlayan Gökalp, Fransızca derslerini İdadi hocalarından Yorgi Efendi'den almıştır. Kendisinde felsefe merakını uyandıran da yine Yorgi Efendi olmuştur. ${ }^{25}$

19 Tuncay, a.g.e., s. 20-21; Enver Behnan Şapolyo, Ziya Gökalp Itttihadı ve Terakki Meşrutiyet Tarihi, İstanbul, 1943, s. 75.

20 Tanyu, a.g.e., s. 9.

21 Tütengil, a.g.e., s. 12; Tuncay, a.g.e., s. 21

22 Tuncay, a.g.e., s. 31; Ali Nüzhet, a.g.e., s. 27-33.

23 Ali Nüzhet, a.g.e., s. 33-40.

24 Tuncay, a.g.e., s. 42.

25 Ülken, a.g.e., s. 304. 
Düşünsel bir süreç olarak, Genç Türkler ve İttihat ve Terakki ile Ziya Gökalp'in düşünce ve ilişki yakınlığı askeri lise yıllarına kadar uzanmaktadır. İmparatorluğun içinde bulunduğu bunalımlar birçok mektep öğrencisi gibi Gökalp'i de derinden etkilemiştir. Bu nedenle Gökalp, okul yıllarından itibaren ülke sorunlarıyla ilgili konulara yakın ilgi göstermiş; yaşamı boyuca birçok siyasi ve sosyal örgütlenme içerisinde yer almıştır.

Başlangıçta Fransız filozof Alfred Foulille'nin etkisinde kalmasına rağmen, Durkheim sosyolojisinin iyi bir okuyucusu ve takipçisi olan Gökalp, bu ekolün etkisiyle "Türk Sosyoloji Ekolü"nü kurmuştur. ${ }^{26}$ Yine, pozitivist bir yönü de olan Gökalp'in, topluma doğru bir yönelim gösteren toplumsal teoremi üzerinde de Durkheim'ın görüşleri belirleyici olmuştur. ${ }^{27}$

Ziya Gökalp'in düşünce dünyasında Selanik önemli bir yer tutmuştur. Gökalp, Selanik'e gidişinden sonra daha önce savunduğu düşüncelerin pek çoğunu terk etmiştir. Bununla birlikte, medreselerin düzeltilmesi ve eğitimde yenileşme gibi yazılarında sıkça savunduğu bazı düşüncelerinden vazgeçmemiştir. ${ }^{28}$

İttihat ve Terakki tarafından Selanik'e tayin edilmesi, Ziya Gökalp'in hayatında yeni bir dönüm noktası olmuştur. Bu dönemde, dilde Türkçülüğü savunan Genç kalemler grubuna katılmış; bu dergide, dilde Türkleşme ile ilgili yazılar yazmaya başlamıştır. Burada, özellikle Ömer Seyfettin'den etkilenen Gökalp, artık Türkçü Gökalp'tir. ${ }^{29}$

Gökalp'in dil çalışmalarına katılmasıyla, dilde yenileşme ve Türkçeleşme çalışmaları hız kazanmıştır. Çünkü Ona göre tüm toplumsal faaliyetlerin yegâne temeli lisandır. ${ }^{30}$ Kültürü ve kültürü ortaya çıaran dili, millet olmanın en önemli unsurları arasında kabul eden Gökalp, dilde Türkleşme olmazsa, vicdanların, dinin ve vatanın parçalanacağını düşünmektedir. ${ }^{31}$ Dilde yenileşmenin ve Türkçülüğün bir karşıllı̆ı olarak "arı Türkçecilik" ifadesini kullanan Gökalp; arı Türkçeciliği, dilin Arap ve Fars köklerinden arındırılarak, bunların yerine Türkçe köklerden yeni eklerle yapılacak yeni Türkçe

26 İlk yazılarını "Diyarbakır" gazetesinde yayınlayan Gökalp, bu dönemde Osmanlı milliyetçiliğini savunmuştur. Ziya Gökalp’in bu yazılarında Gabriel Tarde'nin etkileri görülmektedir bkz. Ülken, a.g.e., s. 305.

27 Heyd, a.g.e., s. 38-39.

28 Hasan Ali Koçer, Türkiye'de Modern Eğitimin Doğuşu ve Gelişimi (1773-1923), İstanbul, 1991, s. 176.

29 Ülken, a.g.e., s. 306-307.

30 Ziya Gökalp, Türkleşmek İslamlaşmak Muasırlaşmak, Sadeleştiren: Yalçın Toker, İstanbul, 1997, s. 55.

31 Ali Nüzhet, a.g.e., s. 51. 
kelimelerin kullanılması olarak tanımlar. ${ }^{32}$ Buna karşın, karşılıkları bulununcaya kadar, sözcük ve terimlerin Arapça ve Farsçalarının kullanılmasını önerir. Burada Gökalp'in, dili, ilintili bağlarından hemen koparmanın zorluğuna ve sakıncalarına yaptığı vurguyu belirtmek gerekir. Böylece, dilde ve kültürde özden beslenen bir dinamizm yakalamak isteyen Gökalp, Türkleşmek, İslamlaşmak ve Muasırlaşmak ilkesi çerçevesinde Türkçeyi, anlam bakımından modernleştirmek, terim bakımından İslamlaştırmak, gramer ve yazın bakımından ise Türkleştirmek gerektiğini belirtmiştir. ${ }^{33}$ Türkleşmek, İslamlaşmak, Muastrlaşmak isimli eserinde de bu durumu, "Türk milletindenim, İslam Ümmetindenim, Avrupa Medeniyetindenim" ifadesi ile ortaya koymuştur. ${ }^{34}$ Ziya Gökalp'in "Türk ulusuna, İslam dinine ve Batı uygarlığına dahiliz" şeklinde yaygın bir sunuş haline getirdiği söylemin, aynı dönemlerde benzer siyasal, ekonomik ve kültürel etkileri duyan Yusuf Akçura ve Hüseyinzade Ali tarafından da gündeme getirildiği görülmektedir. ${ }^{35}$ Yine burada da, oldukça geniş bir coğrafyada, zengin ve dinamik kültür dünyas1na sahip; ekonomik, siyasal ve askeri açıdan çok güçlü bir İmparatorluk sürecinden; siyasal, kurumsal, ekonomik ve askeri bunalımlarla birlikte geriye çekilme/ulus sürecine geçme sorunlarına karşı teori üretme ve çözüm arayışlarının etkili olduğunu belirtmek gerekir.

Dolayısıyla, Ziya Gökalp'in siyasal düşünceleri ile dönemin siyasal olguları arasında paralel bir ilişkinin bulunduğunu söylemek mümkündür. İlk dönemlerinde Osmanlıcılık ve ümmetçilik anlamında olmasa bile, İslamc1lık düşüncelerine de ilgi gösterdiği bilinen Gökalp’in milliyetçilik anlayışı ile modern ulus-devletin ve yeni Cumhuriyetin kurucu iradesinin benimsediğ i milliyetçilik anlayışları arasında büyük bir örtüşme vardır. Gökalp’e göre, milleti oluşturan değerlerin başında dil birliği, kültürel paylaşım ve din gelmektedir. ${ }^{36}$ Bir başka ifadeyle Gökalp, bir kültür milliyetçiliğini öngörmekte, millet olabilmek için etnik ayrıştırmalara ilgi göstermemektedir. Buna, Gökalp, 'kültür milliyetçiliği' adını vermektedir. Böylece Gökalp, dünya ve coğrafi gerçeklere uygun bir millet tanımlamasına gitmektedir. Cumhuriyetin kurucu iradesi tarafından benimsenen Gökalp'in bu milliyet(çilik) yaklaşımı, başta Birleşik Amerika olmak üzere, çağdaş toplumlarda da varlık ve önemini devam ettirmektedir. Yer yer öne çıkarılan etniklik ve yerellikle, ulus olgusu ve uluslaşma bilincinin birbirinden çok farklı şeyler olduğunun

32 Ziya Gökalp, Türkçülüğün Esasları, Hazırlayan: Mehmet Kaplan, İstanbul, 1972, s. 11.

33 Gökalp, Türkleșmek İslamlaşmak Muasırlaşmak, s. 13; Koçer, a.g.e., s. 177.

34 Gökalp, a.g.e., s. 3.

35 Heyd, a.g.e., s. 154-155.

36 Gökalp, Türkleşmek İslamlaşmak Muasırlaşmak, s. 50-51. 
açık olarak vurgulandığı günümüzde; Gökalp'in ortaya koyduğu ulus tanımlamasının geçerliği daha iyi anlaşılır olmaktadır.

Ziya Gökalp'in, ulus olmanın gereklerinden biri olarak belirttiği din birliği ile dindaşlığa dayanan birlik birbirinden farklıdır ve zaten Gökalp; 'ümmet' olarak tanımlanan dindaşlık birlikteliğine de karşıdır. ${ }^{37}$ Ona göre; din, birbirinden farklı coğrafyalarda, farklı kültür dünyalarında ve değişik toplumlarda aynı olabilir; ancak, millet olmak için din birlikteliğinden başka kültür ve dil birliği de gerekmektedir ki; kültür birlikteliği için ortak toplumsal deneyimler, paylaşımlar, duyuş ve düşünüşlere ihtiyaç vardır.

Bu çerçevede; din dilinin de Türkçeleşmesi gerektiğini savunan Gökalp'in bu yaklaşımı, Cumhuriyet'in kuruluşunu takip eden ilk onlu yıllarda bir dönem yaşama da geçmiştir. Merkezi bir din hizmetleri idaresinin kurulmasında (Diyanet İşleri Başkanlığı) olduğu gibi, birçok Cumhuriyet kurumunun yanı sıra, siyasal, kültürel ve dinsel uygulamaların ortaya çıkışında da yine Gökalp'in etkilerinin olduğu muhakkaktır. ${ }^{38}$

Buradan hareketle, ikinci meclise de seçilen Ziya Gökalp ile Atatürk arasında bir ilişki yakınlığı olmasa bile; düşünsel paralelliklerin ve paylaşımların olduğu açıktır. Zira hastalığının ilerlemesi üzerine, masrafları Devlet tarafından karşılanmak üzere yurt dışında tedavi olmasını öneren Atatürk'ten; tedavi masraflarını değil, kendisinden sonra ailesine yardım edilmesini isteyen Gökalp'in bu isteği, Atatürk'ün önerisi üzerine Meclis tarafından ç1karılan bir kanunla yerine getirilmiştir. ${ }^{39}$

Yoğun bir şekilde kültür milliyetçiliği vurgusu yapan Gökalp, etnik milliyetçiliğe/ırkçılı̆̆a karşı bir düşünce yapısına sahip olmuştur. Ona göre, toplumların karakterleri kalıtımsal değil, kültür ve eğitim yoluyla şekillenmektedir. Gökalp’in ırkçılığa karşı oluşu, düşünsel ve sosyal gerçeklikle bir iç içeliğe sahiptir. ${ }^{40}$ Gökalp bu yargıya, toplumların, özellikle Türk toplumunun yapısını ve sosyal gerçekliklerini değerlendirerek varmıştır.

Ziya Gökalp'in Cumhuriyet ve demokrasi düşüncelerinde de bir değişme süreci söz konusudur. Padişah aleyhine yürüttüğü söylemlerini meşrutiyetin ilanıyla birlikte askıya alan Gökalp, savaş dönemlerinde de vatan ve dinin selameti için Halife Sultana dualarda bulunmuştur. ${ }^{41}$ Bununla birlikte Gökalp, hiçbir zaman özgürlükçü ve halkçı tutumundan vazgeçmemiştir. Onun hemen her yazı ve şiirinin ana teması vatan, ulus, hürriyet, Ulusun eğitimi ve uyanışı üzerine olmuştur.

37 Heyd, a.g.e., s. 54

38 www.bilimarastirmavakfi.org/html2/yayinlar/cumhuriyetcilik.html, (12.11.2006).

39 Heyd, a.g.e., s. 27.

40 Heyd, a.g.e., s. 53-54.

41 Heyd, a.g.e., s. 140. 
Ziya Gökalp düşüncesinde, Türkçülük ayrı bir yere sahiptir. Zira, Gökalp'in çalışmaları hep Türk toplumunun geçmişi, günü (kendi dönemi) ve geleceği ile Türk dili ve Türk kültürü üzerinde yoğunlaşmıştır. Bu duygu ve düşüncelerle $\mathrm{O}$, bilimsel, ahlaki, kültürel ve felsefi bir Türkçülük anlayışı ortaya koymuştur. ${ }^{42}$

Gökalp'in 1908 yılından sonra Türk Milliyetçileri arasına katılması ile ulusçuluk bir sistem haline gelmiştir. 18 yll Türk toplumunun sosyal ve kültürel yapısı üzerine çalışan Gökalp, bu birikimini Genç kalemler dergisinde, özellikle de 'Turan' şiiri ile dile getirmiştir. Bilimsel bir Türkçülük ortaya koyan Gökalp, Türkçülüğün Esasları'nda Türkçülügü̈ “Türkçülük, Türk milletini yükseltmektir" diye tarif etmiştir. ${ }^{43}$ Ona göre Türkçülüğün yakın ve uzak olmak üzere iki hedefi vardır. Yakını 'Oğuz ya da Türkmen Birliği'; uzağı ise 'Turan'dır. ${ }^{44}$ Türkçülüğünün ülküsünü de 'Türkiyecilik', 'Oğuzculuk ya da Türkmencilik' ve 'Turancılık' olarak üç ana bölüme ayıran Gökalp, Cumhuriyetin ilanından sonra son ikisinden vazgeçmiş ve ülkünün 'Türkiyecilik’ olduğunu belirtmiştir. Türk toplumu için uygun gördüğü Türkçülük ise toplumsal Türkçülük olmuştur. Onun Türkçülüğünde, halka doğru gitmek ayrı bir öneme sahiptir. Halka hem ondan hars almak hem de medeniyet götürmek için gidilir. ${ }^{45}$

Medeniyet-hars ayrımı onun en dikkat çekici görüşlerinden birini oluşturur. Hars, yani kültür, ona göre milli; medeniyet, yani; uygarlık ise evrenseldir. Uygarlığın kültürden sonra ve onun eseri olduğunu savunan Gökalp, Türkçülüğün Esasları'nda kültürü oluşturan unsurları sekiz bölümde incelemiştir. Bunlar; dilde, estetikte, ahlakta, hukukta, dinde, ekonomide, siyasette ve felsefede Türkçülüktür. ${ }^{46}$

Sonuç olarak, Ziya Gökalp, Türk düşünce, kültür ve siyaset tarihinin önemli simalarından biridir. İmparatorluk sürecinden Ulus-Devlete geçiş döneminde yaşayan Gökalp'in, karşılaşılan sorunlar ve bunalımların da etkisiyle Türk toplumu ve Türk kültürü üzerine ortaya koymuş olduğu sosyolojik, kültürel ve siyasal teori ve değerlendirmeler bugün bile gerçekliğini devam ettirmektedir. Zira Gökalp'in birçok siyasal, dinsel ve kültürel düşünce ve önerileri yeni kurulan Cumhuriyet ile birlikte yaşama geçme olanağı bulmuştur. Gökalp'in bu toplumsal yaklaşımları üzerinde Batılı algıların da etkili olduğu muhakkaktır.

42 Ali Nüzhet, a.g.e., s. 120, 134.

43 Gökalp, Türkçülüğün Esasları, s. 16.

44 Tuncay, a.g.e., s. 89.

45 Gökalp, Türkçülüğün Esasları, s. 41-42; Ali Nüzhet, a.g.e., s. 134.

46 Gökalp, Türkçülüğün Esasları, s. 113-188. 